http://dx.doi.org/10.11646/zootaxa.3669.4.9

http://zoobank.org/urn:1sid:zoobank.org:pub:437E95D5-93D8-41A8-83AE-AEB6B585E509

\title{
A giant foraminifer that converges to the feeding strategy of carnivorous sponges: Spiculosiphon oceana sp. nov. (Foraminifera, Astrorhizida)
}

\author{
MANUEL MALDONADO ${ }^{1,4}$, MARÍA LÓPEZ-ACOSTA, CÈLIA SITJÀ, RICARDO AGUILAR ${ }^{2}$, \\ SILVIA GARCÍA ${ }^{2} \&$ JEAN VACELET ${ }^{3}$ \\ ${ }^{1}$ Centro de Estudios Avanzados de Blanes (CEAB-CSIC), Acceso Cala St. Francesc 14, Blanes 17300, Girona, Spain \\ ${ }^{2}$ OCEANA, Leganitos 47, Madrid 28013, Spain \\ ${ }^{3}$ IAix Marseille Université, CNRS IMBE UMR 7263, Station Marine d'Endoume, rue Batterie des Lions, 13007 Marseille, France \\ ${ }^{4}$ Corresponding author. E-mail: maldonado@ceab.csic.es
}

\begin{abstract}
The foraminifer Spiculosiphon oceana sp. nov. is a giant $(>4 \mathrm{~cm})$ agglutinated astrorhizid, which makes the second known species of this unusual genus and its first Mediterranean record. It has a peculiar stalked, capitate, monothalamous test. Bleach digestion and X-ray microanalysis indicated the test to be made exclusively of siliceous sponge spicules agglutinated in organic cement. The organism stands on a hollow, $4 \mathrm{~cm}$ long, $0.5 \mathrm{~cm}$ thick stalk built with highly selected, long and thin spicule fragments, tightly cemented together in parallel to the main axis of the stalk. The proximal end of the stalk is closed and slightly expanded into a bulb-like structure, designed to penetrate between the sand grains and maintaining the test upright while avoiding a permanent attachment to the substratum. The distal stalk end becomes a hollow, globelike structure that contains the main protoplasm. The globelike region is built with loosely agglutinated and irregularlyshaped spicules, allowing extrusion of the pseudopodia through the cavities between the spicules. The globelike structure also serves as an anchoring basis, from which long and thin, solid tracts protrude radially to make a spherical crown that attains about $4 \mathrm{~mm}$ in total diameter. The radiating tracts are built with highly selected aciculate spicule fragments held together with a translucent organic cement. They provide skeletal support for the extension of a crown of pseudopodia into the water column. This arrangement is thought to enhance the chances of the pseudopodia to contact demersal planktonic prey. In summary, Spiculosiphon species collect and arrange sponge spicules with high selectivity to recreate a body morphology that strongly converges to that of some carnivorous sponges, which allows these predatory foraminifera to exploit a prey capturing strategy similar to that of the carnivorous sponges. This idea is also consistent with our report of an additional, yet undetermined, Spiculosiphon species occurring in the same sublittoral Mediterranean cave where carnivorous sponges were first discovered.
\end{abstract}

Key words: adaptive test, astrorhizid, agglutinated, siliceous test, sponge spicule, benthic foraminifera, silica, tellurium, collagen-like cement, bioturbation

\section{Introduction}

Agglutinated foraminifera make a relatively diverse group of organisms, which is taxonomically defined as a subclass (Textulariia) and comprises four orders. The orders are based upon gross morphology, wall structure, and cement composition (Kaminski 2004). The cement that binds the test together may be organic (as in the Astrorhizida), calcareous and canaliculate (as in the Textulariida), or of mixed nature, containing organic, calcareous, and microgranular types (as in the Lituolida and Loftusiida). Some of the agglutinated foraminifera build their test collecting partially or exclusively siliceous sponge spicules from the sea bottom. Although the fossil record clearly indicates that test morphology in the agglutinated foraminifera is species specific and does not vary over large time scales, little is known about the adaptive advantages that select for a particular shape (Bowser et al. 1995; Hohenegger 2009; Marszalek et al. 1969). Here we report on a new, large astrorhizid species using exclusively organic cement and sponge spicules to build a distinctive test that appears to replicate not only the body shape of carnivorous sponges but also its functionality as feeding strategy. 


\section{Material and methods}

The studied material was collected at the "Seco de Palos" sea mountain $\left(37^{\circ} 36.333^{\prime} \mathrm{N}, 00^{\circ} 01.869^{\prime} \mathrm{W}\right.$; Western Mediterranean, Spain) during the "EXOCED12" Expedition conducted by OCEANA in October 2012. The cruise was addressed to explore western Mediterranean deep shelves using a remote operated vehicle (ROV). The foraminifera were, therefore, unexpectedly collected when assaying a van Veen grab on a soft bottom mostly consisting of detrital sand, at $153 \mathrm{~m}$ deep. In the absence of fixing or preserving solutions, the foraminifera were initially maintained in seawater for several hours after collection and finally fixed/preserved in pharmacy $90 \%$ ethanol upon arrival to harbor.

To prevent further damage, the specimens were morphologically studied within $90 \%$ ethanol-filled, microbiological Petri dishes, using a SZX12 Olympus dissection microscope and an IX51 inverted compound microscope equipped with a C7 ProgRes digital camera. Small portions of the various regions of the test were dissected and dissolved in commercial bleach to investigate spicule composition under the compound microscope. Additionally, two air-dried, uncoated stalks were mounted on an aluminum stub and studied under a HITACHI TM300 Scanning Electron Microscope (SEM) equipped with an Energy Dispersive X-Ray Spectrometer (EDS), which allowed qualitative and quantitative elemental microanalysis of the test wall. Only significant acquisition signals for periods longer than $180 \mathrm{~s}$ were considered in the analyses. The relative abundances of the detected elements were expressed as atomic percentages.

Because non-destructive light microscopy methods were sufficient to describe and illustrate with enough resolution the main features of the collected material, SEM was only applied to stalks of fragmentary individuals, but not used on the holotype and the paratype to prevent irreversible damage. Transmission Electron Microscopy (TEM) to investigate the cytology was not attempted, because the initial deficient fixation of the collected material was inappropriate to guarantee preservation of the cell ultrastructure.

All collected and studied material has been stored at the National Museum of Natural Sciences of Madrid (MNCN-CSIC).

\section{Systematic description}

\section{Kingdom Chromista}

\section{Phylum Foraminifera d'Orbigny, 1826}

\section{Order Astrorhizida Lankester, 1885}

\section{Family Schizamminidae Nørvang, 1961}

The current high-rank classification of Foraminifera has not yet caught up with recent molecular and morphological phylogenies and many uncertainties remain. Most molecular phylogenies depict the Foraminifera as a monophyletic subclade within the more inclusive clade Chromista (as defined by Cavalier-Smith, 2010). However, within the Foraminifera, the Astrohrizida has been shown to be a polyphyletic taxon. "Astrorhizids" are dispersed throughout a paraphyletic array of single-chambered foraminiferans that were traditionally grouped in the order Allogromiida (Habura et al. 2008; Lecroq et al. 2011; Loeblich \& Tappan 1988; Pawlowski et al. 2003; Sen Gupta 2002; Tsuchiya et al. 2013). In the absence of an updated classification scheme that integrates recent molecular and morphological views, we have decided not to leave the material described in this study without a high-rank taxonomic allocation and tentatively followed the classification scheme currently provided at the World Modern Foraminifera database "http://www.marinespecies.org/ foraminifera", where the schizamminids consist of 3 valid, extant genera: Jullienella Schlumberger, 1890, Schizammina Heron-Allen \& Earland, 1929, and Spiculosiphon Christiansen, 1964. Collectively, the family is small, with only 11 known species to date, 3 of which belong to Jullinella, 6 to Schizammina, and 2 to Spiculosiphon (if considering the new species described herein). We are, however, aware that the current concepts of "Astrorhizida" and "Schizamminidae" can be profoundly altered in the coming years. 


\section{Genus Spiculosiphon Christiansen, 1964}

Definition modified from Christiansen (1964) to incorporate the shared features of the new species described herein. Large ( $>20 \mathrm{~mm}$ ) astrorhizid foraminifera characterized by a capitate, stalked, monothalamous test, the wall of which is made mostly or exclusively from siliceous sponge spicules agglutinated in an unidentified, organic cement. The stalk consists of a simple or dichotomized (during asexual reproduction), hollow tube that may stand upright respect to the substratum, but never attaches permanently to it. The wall of the stalk is built with elongated fragments of sponge spicules, tightly glued together in parallel to the major axis of the stalk. The stalk end opposite to the substratum becomes a globelike, central structure, from which long, thin tracts made of elongated spicule fragments radiate outwards. This capitate portion of the body is herein defined as being distal, opposite to the proximal stalk end, which is the one contacting the sea bottom. Asexual reproduction appears to be by budding or by fission. Sexual reproduction never observed. Type species: Spiculosiphon radiata Christiansen, 1964, from Norway, $100 \mathrm{~m}$ depth.

\section{Spiculosiphon oceana sp. nov.}

Etymology. The species name "oceana" is to honor the non-profit organization for ocean conservation OCEANA, which was responsible for the field collection of the type material.

Diagnosis. Non-attached, stalked and capitate test exclusively built with siliceous sponge spicules that are agglutinated together by organic cement. Undivided, hollow stalk, which slightly expands into a closed, bulb-like structure at the end contacting the substratum (proximal pole of the body). The radiating spicule tracts projecting from the central, globelike structure are always linear, never subdivided nor plumose.

Type material. The holotype (MNCN-33.11/2; fig. 1A) and the paratype (MNCN-33.11/3; fig. 1B) were complete organisms; five additional fragments, consisting of only the stalk or bearing a small, damaged portion of the globular part of the test, were stored as additional material (MNCN-33.11/4); two stalk fragments mounted on conductive transfer tape glued onto a SEM aluminum stub were also deposited in the collection (MNCN-33.11/4).

Morphology. Stalked and capitate, monothalamous test (fig. 1A). The capitate region of the test consisted of a central, hollow sub-sphere built with a large morphological variety of sponge spicules, which were loosely and irregularly agglutinated (fig. 1B-C). This globelike structure measured $1825 \mu \mathrm{m}$ and $1250 \mu \mathrm{m}$ in diameter in the holotype and paratype, respectively. The spicules at the globelike structure included small needle-like fragments, but also four-rayed forms (i.e., cladomes of diverse triaene types; fig. 2A-C), along with laminated fragments derived from discotriaenes and even pieces of hypersilicified desmata (not shown). Spiny spicules (acanthostyles) and microscleric spicules (e.g., diancistra of hamacanthid demosponges) were also observed when part of the globelike region of the test of a fragmentary specimen was dissolved in bleach (not shown). Irregular hollows and cavities were noticed in between the loosely agglutinated spicules that made the wall of the globelike structure (fig. 1C, 2B). These cavities appeared to result from an erratic selection and chaotic arrangement of the agglutinated sponge spicules rather than being distinct apertures elaborated by the cell.

Between 20 and 30 tracts made with agglutinated spicule fragments protruded radially from the globular centre, extending 1 to $3 \mathrm{~mm}$ outwards, and making the capitate region to reach about 3 to $4.5 \mathrm{~mm}$ in total diameter (fig. 1A-B). These radiating spiculated tracts were less than $60 \mu \mathrm{m}$ in total thickness, built by overlapping 1 to 3 , relatively thin and long, spicule fragments (fig. 2D). Unlike in the central globelike zone of the test, the spicule fragments used for the radiating tracts indicated high selectivity, being typically fragments of oxeas and styles, but also long-shafted triaenes with small cladomes. It is worth noting that whereas the cement agglutinating the spicules of the globular region was never evident under the compound microscope, the spicules of the radiating tracts were noticed to be held together by a translucent, quite evident cementing substance (fig. $2 \mathrm{E}-\mathrm{G}$ ), resembling the nodal spongin of demosponges.

The stalk was hollow, typically longer than $3.5 \mathrm{~cm}$ and averaging $500 \pm 50 \mu \mathrm{m}$ in external diameter (fig. 1A). No agglutinated material other than siliceous sponge spicules was observed to build the wall at the stalk (fig. 3AB). There was the "quasi" exception of a small calcareous foraminifer on one of the stalk fragments. Nevertheless, it was not actually embedded or integrated in the spicule wall, but attached externally to an already formed spicule wall (fig. 1D, 3C). As the radiating tracts, the stalk was built with highly selected, needle-like 

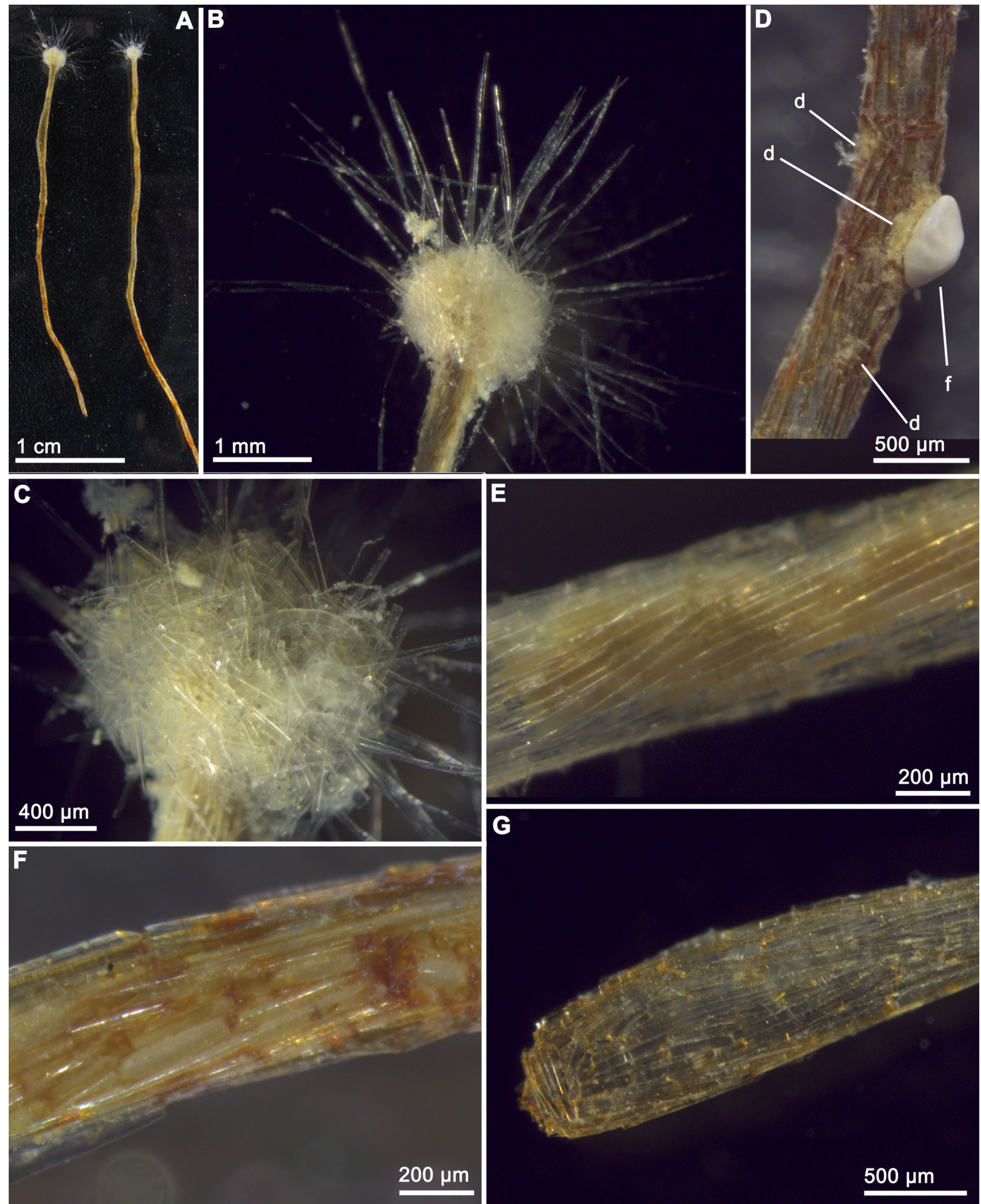

FIGURE 1. (A) General view of the holotype and the paratype (from left to right, respectively) of Spiculosiphon oceana sp. nov. (B) Detail of capitate region of the holotype, showing the globelike, central structure and the radiating tracts of spicules. (C) Globelike region of the holotype, showing the irregular, loose arrangement of spicules. (D-F) Views of stalks. One of the collected stalks (D) had a calcareous foraminifer (f) attached and also some flocculated debris (d). The stalk in E shows the tightly packed spicules to be slightly twisting with respect to the stalk axis. The stalk in $\mathrm{F}$ shows a region in which the translucent spicule wall gets a brownish to purplish coloration. $(\mathrm{G})$ Detail of the proximal end of a stalk, showing that it is a closed structure, slightly expanded into a bulb-like form. 

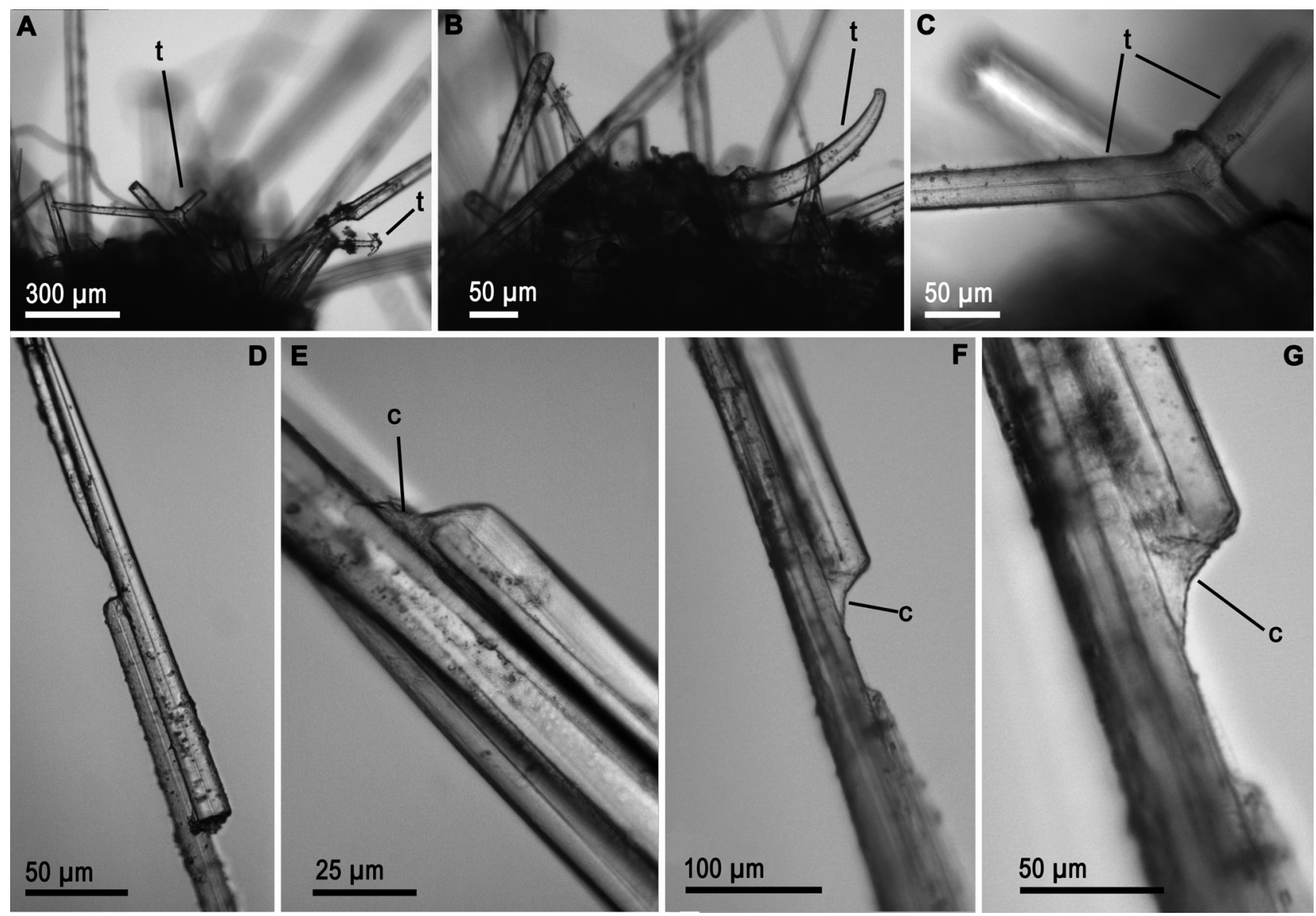

FIGURE 2. (A-C) Compound microscope micrographs showing the irregular arrangement of the spicules at the surface of the central globelike region of the test. Note the presence of needle-like spicule fragments along with three-rayed and four-rayed spicules $($ triaenes $=\mathrm{t}) .(\mathrm{D}-\mathrm{G})$ Views of the radiating tracts built by overlapping 2 to 3 spicules, which are held together by a translucent cement (c).

spicule fragments (occasionally including some long-shafted triaenes; fig. 3C), which were tightly agglutinated together (fig. 1E-F). The spicule fragments run almost in parallel to the direction of the major stalk axis, but slightly twisting around it (fig. 1E). Along the entire stalk, orifices or cavities were never noticed, except in those cases of accidental damage derived from collection or laboratory manipulation of the organisms (fig. 3A). SEM observations at broken portions of the stalks revealed that the test wall consists of spicules arranged in a single layer (not shown). Some of the spicules incorporated to the test showed incipient dissolution scars (pits) at their silica surface (fig. 3A). It was also noticed that the proximal end of the stalks was never attached to gravel pieces or rocks, being a closed structure that slightly expanded into a bulb-like form (figs. 1G, 3B).

Light microscopy and SEM observations revealed that some organic material (debris) flocculated on the external side of the stalks at some areas (figs. 1D; 3A, C). However, no obvious cementing material was ever noticed among the spicules when the external side of the tests was studied under light and scanning electronic microscopy (fig. 1E; 3A-C). When studying the stalk under light microscopy, discontinuous areas of brownishpurplish coloration were noticed (figs. 1D-G). SEM observations corroborated that those color tinges derived neither from mineral coatings laying at the external side of the test nor from organisms fouling the test. Rather, the irregular patchiness of coloration (figs. 1D-G) strongly suggested that the color probably derives from photosynthetic symbionts growing at the internal side of the highly translucent siliceous test (see Discussion).

X-ray microanalysis of the test. The exact nature of the cement agglutinating the sponge spicules of Spiculosiphon oceana could not be resolved in this study. It was corroborated that small portions of radiating spicule tracts, globular test, and stalk readily dissolved their cement in commercial bleach, releasing the agglutinated spicules and, hereby, confirming the organic nature of the cement. X-ray microanalyses on the external side of the stalks revealed occurrence of three detectable elements only (fig. $4 \mathrm{~A})$ : oxygen $(58.8 \pm 1.3 \%)$, 

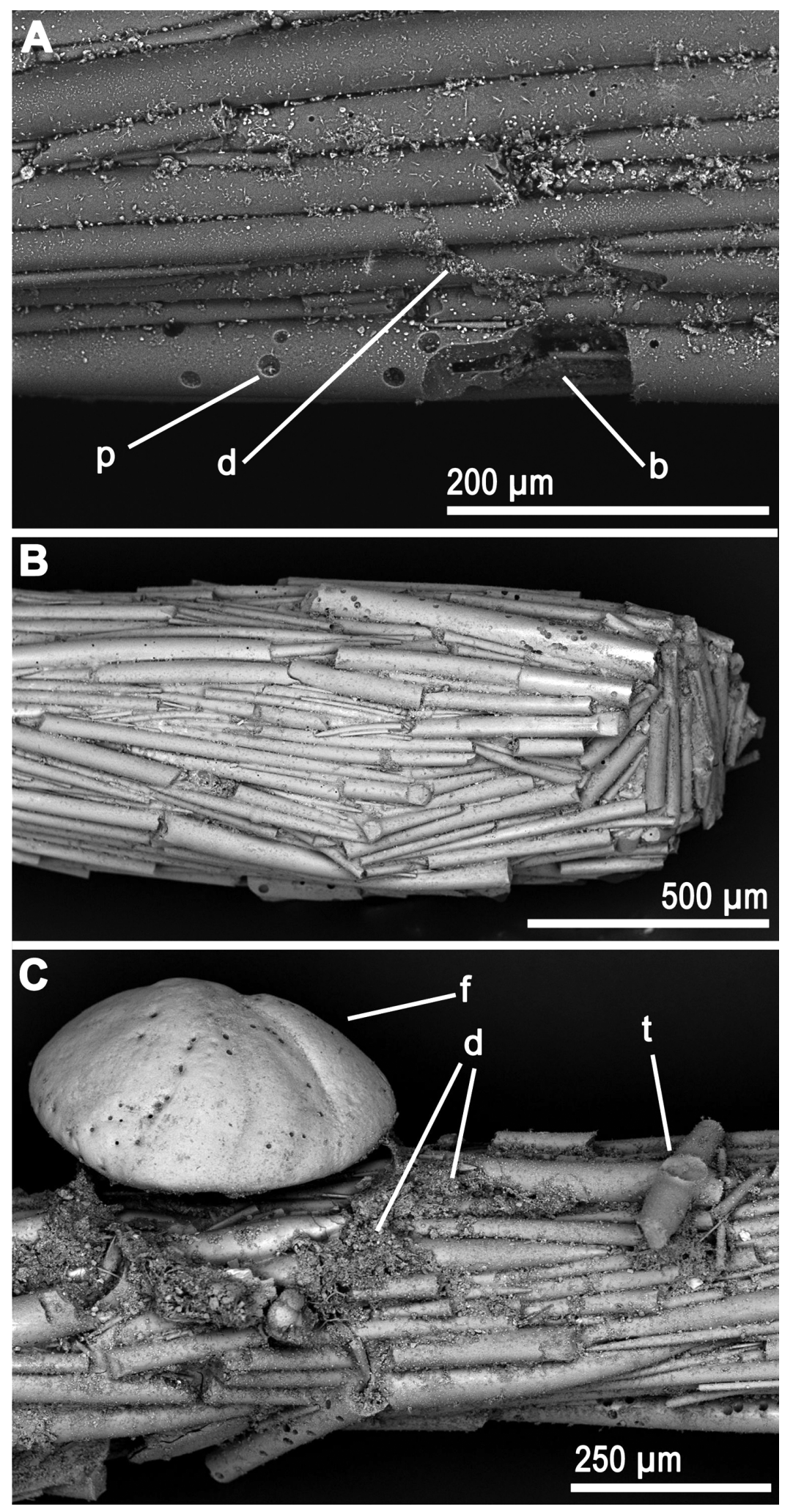

FIGURE 3. SEM micrograph of stalks. (A) Tightly packed needle-like spicule fragments, with no obvious cement between them. Some debris (d) has flocculated on the spicules. Note that the silica of some of the oldest spicules started dissolving, as indicated by the occurrence of tiny cavities and pits (p) at their surface. Dissolution cavities are to be distinguished from accidental breakages (b) caused to the stalk during collection or laboratory manipulation. (B) View of the distal end of the stalk, showing that it is a closed, bulb-like structure. (C) Detail of a calcareous foraminifer (f) externally attached to the wall of one of the collected stalks (see fig. 1D). Note that a triaene $(\mathrm{t})$ has been incorporated into the test and that some debris (d) has flocculated on the stalk. 

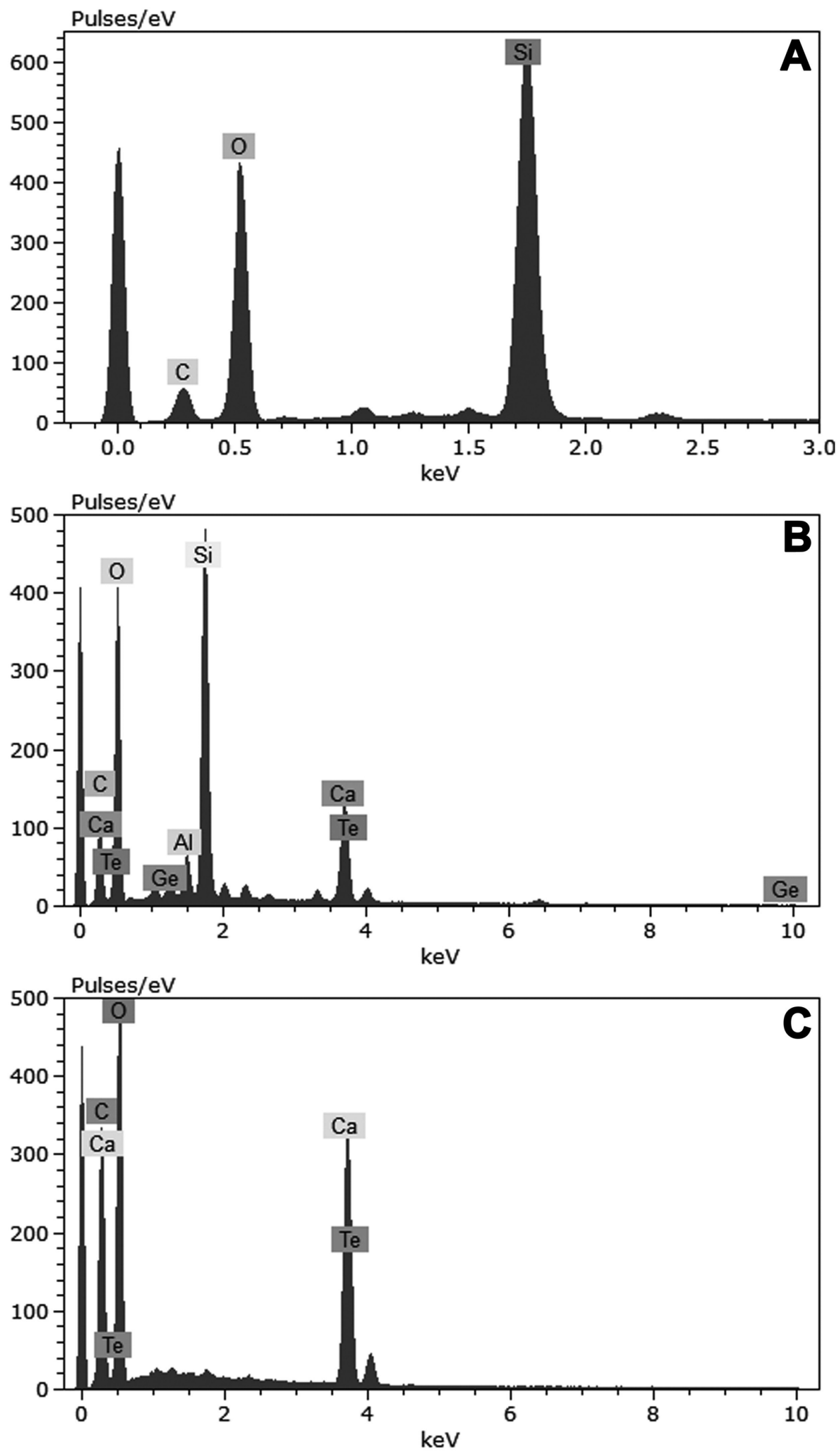

FIGURE 4. Results of EDS microanalysis at (A) the external side of the spicule wall of a stalk of Spiculosiphon oceana, (B) the wall of the stalk at areas bearing debris, and (C) the calcareous test of an unidentified, non-agglutinated, calcareous foraminifer attached to the stalk of $S$. oceana (see also figs. 1D; 3C). 
carbon $(27.8 \pm 0.4 \%)$, and silicon $(13.4 \pm 1.6 \%)$. By considering that all the quantified silicon derived from the spicules' biogenic silica $\left(\mathrm{Si}_{2}\right)$, it can be deduced that about $26.8 \%(=13.4 \times 2)$ of the oxygen is also attributable to the silica, while most of the remaining oxygen $(32 \%=58.8-26.8)$ would be associated to the detected carbon. That is, a bit more than half of the detected oxygen is probably combined with carbon to make the organic cement. A small carbon-oxygen percentage may also derive from occasional organic deposits formed by flocculation of debris on the external side of the stalks (fig. 3A, C). When stalk areas bearing pieces of attached debris were analyzed by EDS microanalysis (fig. 4B), it was found that, in addition to the major expected $\mathrm{O}, \mathrm{C}$, and $\mathrm{Si}$ elements, another two minority elements consistently occurred: $\mathrm{Ca}(2.7 \pm 1.5 \%)$ and $\mathrm{Al}(1.2 \pm 0.3 \%)$. Detection of these two elements was consistent with the presence of abundant organic calcareous debris and aluminum silicate clays at the detrital-sand bottom where the foraminifera lived. In two occasions, the analyzed debris also incorporated S $(0.6 \pm 0.02 \%)$ and $\mathrm{Ge}(0.2 \pm 0.03 \%)$. More surprisingly, tellurium $(\mathrm{Te})$, a quite uncommon element on earth, was once detected $(0.77 \%)$ in the attached debris. Interestingly, 5 out of 9 microanalyses conducted on the test of a calcareous foraminifer attached to a Spiculosiphon oceana stalk (figs. 1D, 3C) also revealed the presence of tellurium $(3 \pm 1.5 \%$; fig. $4 \mathrm{C})$, along with $\mathrm{O}(46 \pm 9 \%), \mathrm{C}(36 \pm 9 \%)$, and $\mathrm{Ca}(15 \pm 5 \%)$.

\section{Discussion}

Spiculosiphon oceana sp. nov. is a giant foraminifer, the largest reported in the Mediterranean to date. It provides the second known species of the unusual genus Spiculosiphon, which so far registered no other record than the description of the type species, Spiculosiphon radiata, collected from a 100m-deep flat of sandy mud at northern Norway ( $70^{\circ} 0^{\prime} \mathrm{N} 19^{\circ} 42^{\prime}$ E, Langsund). Spiculosiphon oceana sp. nov. is morphologically similar to $S$. radiata, but, in the current stage of knowledge, some differences between both species can be noticed. The hollow stalk of $S$. oceana was about twice longer $(>4 \mathrm{~cm})$ than that described for $S$. radiata and formed a closed, bulb-like expansion at its proximal end. Likewise, the slender, radiating spicule tracts projecting from the distal globelike structure of S. oceana, unlike those depicted for S. radiata, were never spiny, plumose nor subdivided.

According to observations on material collected some 18 years ago but never published, it appears that there is a second species of Spiculosiphon in the NW Mediterranean, either S. radiata or an undescribed species (fig. 5). The specimens accounting for this record were collected from the surface layer of muddy sediment in a dark cave (the "3PP cave") near La Ciotat (France), at a depth of $24 \mathrm{~m}$. In this cave, several bathyal invertebrate species occur due to environmental conditions nearly similar to those of the deep Mediterranean, including a year-round stable $13^{\circ} \mathrm{C}$ temperature similar to that of the bathyal zone (Vacelet et al. 1994). The collected specimens were tentatively identified by Dr. Onno Gross as specimens belonging to Spiculosiphon cf. radiata. The shape and general features were clearly similar to those described for Spiculosiphon, showing a stalk built by short, densely agglutinated spicules, mostly monaxonic (fig. 5D-E) and a distal, globelike expansion from which threads sustained by long monaxon spicules are projected radially (fig. $5 \mathrm{~A}-\mathrm{C}$ ). The size of the collected specimen, not exceeding $10 \mathrm{~mm}$ high, was clearly smaller than that known for $S$. radiata (about $2 \mathrm{~cm}$ ) and $S$. oceana $\mathbf{s p . ~ n o v . ~}$ (about $4 \mathrm{~cm}$ ). Unlike in $S$. oceana, the radiating spicule tracts of 3PP specimens were sometimes divided (fig. 5B), in a fashion similar to that illustrated for $S$. radiata. No shell of calcareous foraminifera was found attached to 3PP specimens, in contrast to what is described for $S$. radiata, which fed on calcareous foraminifera and maintained their tests transiently attached to the globelike structure (Christiansen 1964). The 3PP foraminifer became highly fragile after fixation, and the radiating tracts easily broke or were forced to coalesce into a non-natural arrangement when the specimens were mounted onto slides (fig. 5A, C), showing a display quite different from the natural condition (fig. 5B). A more complete study considering freshly collected material would be needed to clarify the species identity of the Spiculosiphon specimens collected from the peculiar 3PP cave.

Since the mid 19th century, test wall structure has been regarded as a key criterion for high-rank classification of agglutinated foraminifera. Bender (1995) proposed an informal classification of agglutinated foraminifera into ones with organic-cement walls and those with low-magnesium calcite cement. Yet, for many groups, there is not a complete identification of the chemical nature of the cement, a lack of knowledge particularly affecting the "astrorhizids". In Spiculosiphon oceana, the organic cement joining the spicules was visible at the radiating tracts, but never at the globelike region and the stalk. The absence of any visible external cement strongly suggested that the spicules were first placed under the desired orientation in the chosen place, then firmly cemented by substances secreted at the internal side of the test. The microanalysis and bleach digestion tests indicated that the cement was 
purely organic (as typically in "astrorhizids"), with no detectable contribution by calcium carbonate or the ferric compounds known in other agglutinated foraminifera (Bender 1995; Kaminski 2004; Lipps 1979). Some authors described the internal sheath in the arenaceous test of the haliphysemid Haliphysema to be a collagen derivative, reporting even the $0.2 \mu \mathrm{m}$-width, cross-striated fibrils characterizing collagens (Hedley \& Wakefield 1967). In some sponge-spicule agglutinating astrorhizids, such Spiculidendron corallicolum Rützler \& Richardson, 1996, the cement was described as being spongin-like, that is, similar to the collagen-derived protein used by demosponges to hold their silica spicules together (Rützler \& Richardson 1996). More recently, Fourier transform infrared spectra and pyrolysis gas chromatography/mass spectrometry products from both collagen and cementing material of some agglutinated saccamminid, trochamminid, and rotaliid foraminifera have been shown to be strikingly similar, supporting that those foraminiferal linings and cements are glycoproteinaceous materials resembling collagen in both structural and molecular form (Allen et al. 2000). Our mere visual comparison between the $S$. oceana cement and the many times observed nodal spongin of demosponge skeletons led us to the impression that the cementing material of at least the radiating spicule tracts of $S$. oceana could well be a collagen derivative. Nevertheless, further histochemical tests and ultrastructural research on properly fixed material would be necessary to support this conjecture.

The microanalyses also provided an anecdotic result, revealing occurrence of tellurium in the test composition of the calcareous foraminifer attached to one of the $S$. oceana stalk. This element had never been reported in foraminifera previously. Indeed, tellurium is an extremely rare element in the Earth's crust and its biological functions are very poorly understood (Ba et al. 2010). Its accumulation has been noticed in some bacteria, fungi, plants, squids and very few other organisms. Given that tellurium was also detected occasionally in debris attached to the stalks of $S$. oceana, it remains unclear whether this element was actively incorporated by the foraminifer protoplasm when building the calcareous test or it was adsorbed into the calcareous matrix from the sediment after death.

In addition to Spiculosiphon, at least nine other genera of agglutinated foraminifera in the super family Astrorhizoidea use spicules at some extent to build their test. Most of these genera use an irregular and little selective combination of sand grains and spicules, such as in the halyphysemids Dendronina Heron-Allen \& Earland, 1922 and Halyphysema Bowerbank, 1862, both with arborescent tests and terminal apertures from which a short crown of sponge spicules radiates; in the hemisphaeramminid Masonella Brady, 1889, with a discoidal test made of agglutinated light coloured quartz sand and sponge spicules in little cement; in the psammosphaerid Psammosphaera Schulze, 1875, with a compressed to spheroid test, consisting of a wall composed mostly of very fine siliceous material, with only occasional sponge spicules in some species; and in the astrorhizid Diffusilina Heron-Allen \& Earland, 1924, with an attached test consisting of silt grains, sponge spicules, quartz sand and mud particles. The saccamminid Technitella Norman, 1878 and Pilulina Carpenter, 1870 are also little selective. The former one builds a thin wall of longitudinally agglutinated sponge spicules and fine quartz grains, or other biogenic particles such as echinoderm plates; the latter one makes a globular test of a relatively thick but flexible wall, agglutinated of loosely aggregated sand and long sponge spicules felted together in a ground mass of finer sand and broken spicules. In contrast, the astrorhizid genus Spiculidendron Rützler \& Richardson, 1996 shows high spicule selectivity to build its arborescent, attached test consisting of exclusively sponge spicules and organic cement, what led to the common name of "spicule tree" for this sponge-imitating foraminifer. The selectivity towards sponge spicules can also vary largely between species within a genus, such as in the rhabdamminid Marsipella Norman, 1878 (=Rhabdaminella de Folin, 1887): some species build a tubular test with a thin wall of agglutinated sand, sponge spicules and tests of other foraminifers, whereas other species collect almost exclusively spicules to make a tubular structure very similar to the stalk of $S$. oceana but measuring only $6 \mathrm{~mm}$ or $7 \mathrm{~mm}$ in length.

As summarized above, a large range of material selection abilities is known across the agglutinated foraminifera. Selectivity appears to be taken at a maximum in the genus Spiculosiphon and particularly in $S$. oceana. First, this organism is somehow chemoselective, being able to discriminate siliceous materials out of the many other materials available at a detrital-sand bottom characterized by abundant particles of calcareous skeletons from bryozoans, deep corals, pteropods, gastropods, bivalves, fish otoliths, and several foraminifera (Globigerinoides ruber, Orbulina universa, etc). Furthermore, S. oceana appears to discriminate very efficiently between biogenic-silica particles of different nature, strongly selecting for siliceous sponge spicules and consistently avoiding siliceous diatom frustules, which were never present in the studied tests. Besides, $S$. oceana strongly selected the shape and size of the materials used for the different parts of the test. Maximum selection was attained at the radiating tracts, where only thin and relatively long spicules occurred. High selection was also 
performed for the stalk, where only elongated spicule fragments were packed in a tight, highly ordered arrangement. At the stalk the spicule pieces were not merely arranged in parallel to major axis of the stalk, but also slightly twisting around it (fig. 1E). As in other natural and man-made support structures, this slightly helical arrangement is assumed to make the stalk more resistant to flexions (e.g., if it is forced by currents, hit by large mobile organisms, etc) than an arrangement strictly vertical and parallel to the major stalk axis. At first sight, the building of the globelike structure could be seen as little selective regarding spicule shapes, because its wall incorporated a large variety of spicule fragments, including multi-rayed forms that had probably been discarded for the radiating tracts or the stalk. Nevertheless, we suspect that the organism strongly selected when building the globelike structure as well. Indeed, it would be selecting for non-linear spicule fragments, probably "aiming" to make a loose, irregular arrangement that leaves cavities among the spicules. Those cavities allow the protoplasm to be extruded to form the pseudopodia.

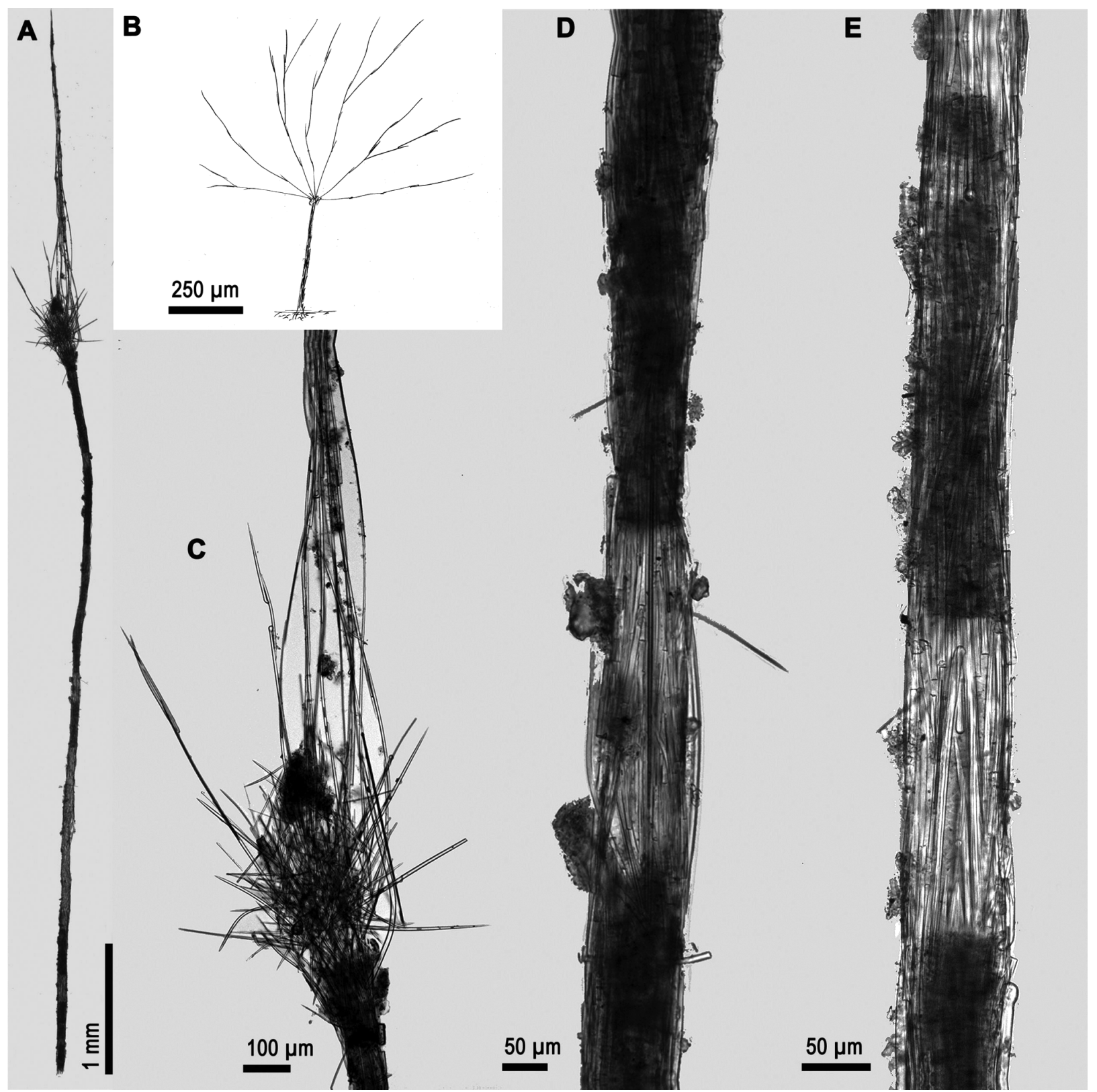

FIGURE 5. Views of Spiculosiphon sp. specimens collected from 3PP cave some 18 years ago. (A) View of whole preserved specimen, with spicule tracts projecting from the spheroid being broken and artificially coalescing. (B) Schematic drawing of a live specimen. (C) Detail of the spheroid portion of the test showing damaged and coalescing, radiating spicule tracts (D-E). Details of the test of the stalk with densely packed spicules and some attached sand grains. 
It remains enigmatic why agglutinated foraminifera commonly use siliceous sponge spicules, and only rarely diatom frustules, which are notably abundant at sea-bottom sediments worldwide (DeMaster 1981). In this regard, it is interesting to recall that agglutinated foraminifera are an old group. Molecular clocks estimate the geological age of the most recent ancestor of the crown clade Foraminifera to be approximately 770 my (650-920 my), during the Cryogenian Period of the the Neoproterozoic Era (Groussin et al. 2011; Pawlowski et al. 2003). The earliest fossil evidence suggest a bit later origin for agglutinated foraminifera, in the latest Pre-Cambrian, some 530 mya (Gaucher \& Sprechmann 1999), just about the same age at which siliceous spicules sponges started appearing in the sediments (Sperling et al. 2010; Yin et al. 2001). It could be that the foraminiferan ability to discriminate biogenic silica co-evolved for many million years associated exclusively to siliceous sponge spicules; diatoms are newcomers that appeared no longer than some 199 mya, in the Early Jurassic (revised in Harwood \& Gersonde 1990). Although the biogenic silica of diatoms and sponges has long been considered to be chemically identical, their drastically different resistances to dissolution strongly suggest differential incorporation of distinctive trace elements or compounds (Kamatani 1971; Maldonado et al. 2005; Maldonado et al. 2012) that foraminifera could somehow detect. The silica of sponge spicules experiences extremely slow dissolution in seawater, being orders of magnitude more lasting than diatom frustules (Maldonado et al. 2005). The fact that some of the spicules cemented in the test showed incipient dissolution scars (pits) at their silica surface (fig. 3A) suggests that they could have been for hundred years in the upper layer of the sediment before being collected. More interestingly, in areas where spicule agglutinating foraminifera are abundant, the continuous use of the same spicules for succeeding generations of these organisms may prevent the spicules to be buried in the sediment at "natural" rates. Therefore, dense populations of agglutinated foraminifera using spicules may bioturbate the "natural" paleostratigraphy of spicule assemblages at a local scale.

It is also interesting that the stalk of $S$. oceana was colored with non-uniform brownish-purplish tinges. This coloration did not come from external debris or fouling organisms. Rather it appeared to derive from symbiotic organisms living beneath the spicule wall, within and/or outside the protoplasm. Siliceous sponge spicules are known to be excellent light transmitters (Cattaneo-Vietti et al. 1996) and facilitate the growth of photoautotrophic symbionts below the spicule wall. Spicule-walled agglutinated foraminifers have been shown to contain intercellularly dinoflagellates (Rützler \& Richardson 1996), as well as diatoms, unicellular chlorophytes, unicellular rhodophytes and/or cyanobacteria (Lee 2006). The reddish-purplish color in S. oceana suggests that the symbionts are dinoflagellates, rhodophytes, or cyanobacteria, but transmission electron microscopy is required to describe the exact nature and location of the putative symbionts. To date, field observations and laboratory experiments agree that large foraminifera may rely importantly on the energy provided by their symbionts to sustain growth (Lee 2006).

We could not conduct "in vivo" observations on Spiculosiphon oceana. Live examination of the test building process in Spiculosiphon radiata by Christiansen (1964) revealed that the youngest individuals were about 100 $\mu \mathrm{m}$-sized masses of protoplasm, which slowly collected sponge spicules for about two weeks to construct first the globelike portion of the test. When the diameter reached some 800 to $4000 \mu \mathrm{m}$, the individuals started to built the stalk, a process that, in laboratory conditions, lasted from only 3 hours to several days. Both Spiculosiphon radiata and $S$. oceana do not appear to be permanently attached foraminifera. While forming the stalk, $S$. radiata individuals were able to move around, placing the body upside-down, that is, the proximal end of the stalk directed upwards while the globelike structure and the radiating spicule tracts contacted the substratum. In this position, the individuals crawled using the pseudopodia emitted through the wall of the globelike portion of the test. Finally, the individuals became erect, standing on the stalk, with the capitate pole of the test directed upwards (Christiansen 1964). It is worth noting that the proximal end of the stalk in S. oceana is closed, expanded in a bulb-like shape, and consistently unattached to sand grains or gravel pellets. We interpret these features to be an adaptation to introduce the stalk in between the detrital sand grains of the soft bottom where it lives. By this mechanism, the foraminifer should be able to stand upright without having the need of being permanently attached. Because detrital sand grains are often highly mobile, small permanently attached organisms are expected to have lower chances of survival. By inserting transiently the proximal end of the stalk in the soft bottom, the foraminifer can stand upright when required for feeding but, in turn, it avoids the drawbacks of permanent attachment, maintaining its ability to move around when required to cope with changes in the microhabitat conditions, to improve access to food preys, to mate sexually, etc. A similar "sessile but not permanently attached" strategy is also used by many cnidarians well adapted to soft bottoms, such as pennatulids in the genera Pennatula Linnaeus, 1758, Pteroeides Herklots, 1858, 
Veretillum Cuvier, 1978, Funiculina Lamarck, 1816, etc. "In vivo" observations on Spiculosiphon specimens from 3PP cave by Dr. Vacelet also confirm this idea. In mud samples collected at $30 \mathrm{~m}$ from the 3PP cave entrance the foraminifera were observed to stand upright at the sediment surface when the sediment was left undisturbed in the laboratory for several hours. It means that the foraminifera were able to recover their natural position (fig. 5B) even when the structure of the upper layer of sediment had been seriously altered during sampling.

Monitoring by Christiansen (1964) on live $S$. radiata revealed that this large foraminifer is a carnivorous predator, feeding on smaller calcareous foraminifera in laboratory conditions, although it probably feeds on other small planktonic organisms. We realized that the morphology of the Spiculosiphon spp. test bears a clear convergence to the body shape of some cladorhizid carnivorous sponges (fig. 6). Two predominant stalked body shapes occur in carnivorous sponges: feathershaped morphology and spiny-headed morphology. The latter is characterized by the distal end of the peduncle becoming a central subspherical or discoid structure, from which a crown of long and thin appendages (filaments) radiates. Feather-like bodies probably enhance the chances to contact small preys that are brought to the sponge plane by steady currents, while spiny-headed bodies are probably more efficient to contact small preys that move erratically in calmed environments. The giant foraminifera in the genus Spiculosiphon are in the same size range that some small sponges of the genus AsbestoplumaTopsent, 1901, and both organisms appear to exploit a similar spiny-headed body shape to maximize their chances to contact small planktonic prey (fig. 6A). The sponge Asbestopluma hypogea Vacelet \& Boury-Esnault, 1996 stands on an attached stalk supported by an internal axis of elongated spicules (Vacelet \& Duport 2004). The stalk ends in a subspheric to discoid mass from which 30 to 60 radiating filaments project outwards. Each filament contains an internal axis made by a tract of long and thin spicules, providing the required skeletal support to hold the filaments extended. The surface of the filaments is provided with siliceous micro-hooks (anisochela spicules), so that the small crustaceans contacting the spherical crown of filaments get trapped (Vacelet \& Duport 2004). We suggest that Spiculosiphon spp. exploits a similar strategy for prey capturing: 1) the organism stands on a long stalk built with collected sponge spicules to enhance its access to demersal planktonic prey; 2) it builds a globelike structure at the distal end of the stalk, which harbors most of the protoplasm and that, in turns, serves as anchoring center to the crown of long spicule tracts; 3) the pseudopodia are extruded through the many cavities in the wall of the globelike structure; 4) relative to other foraminifera, the pseudopodia can be extended further out in the water because of the external support provided by the spicule tracts, hence, increasing the chances of prey capture; 5) it is also likely that the additional support provided by the radiating spicule tracts favors $S$. oceana to capture and transport back to the globelike center larger preys than other predatory foraminifera lacking such a skeletal support.
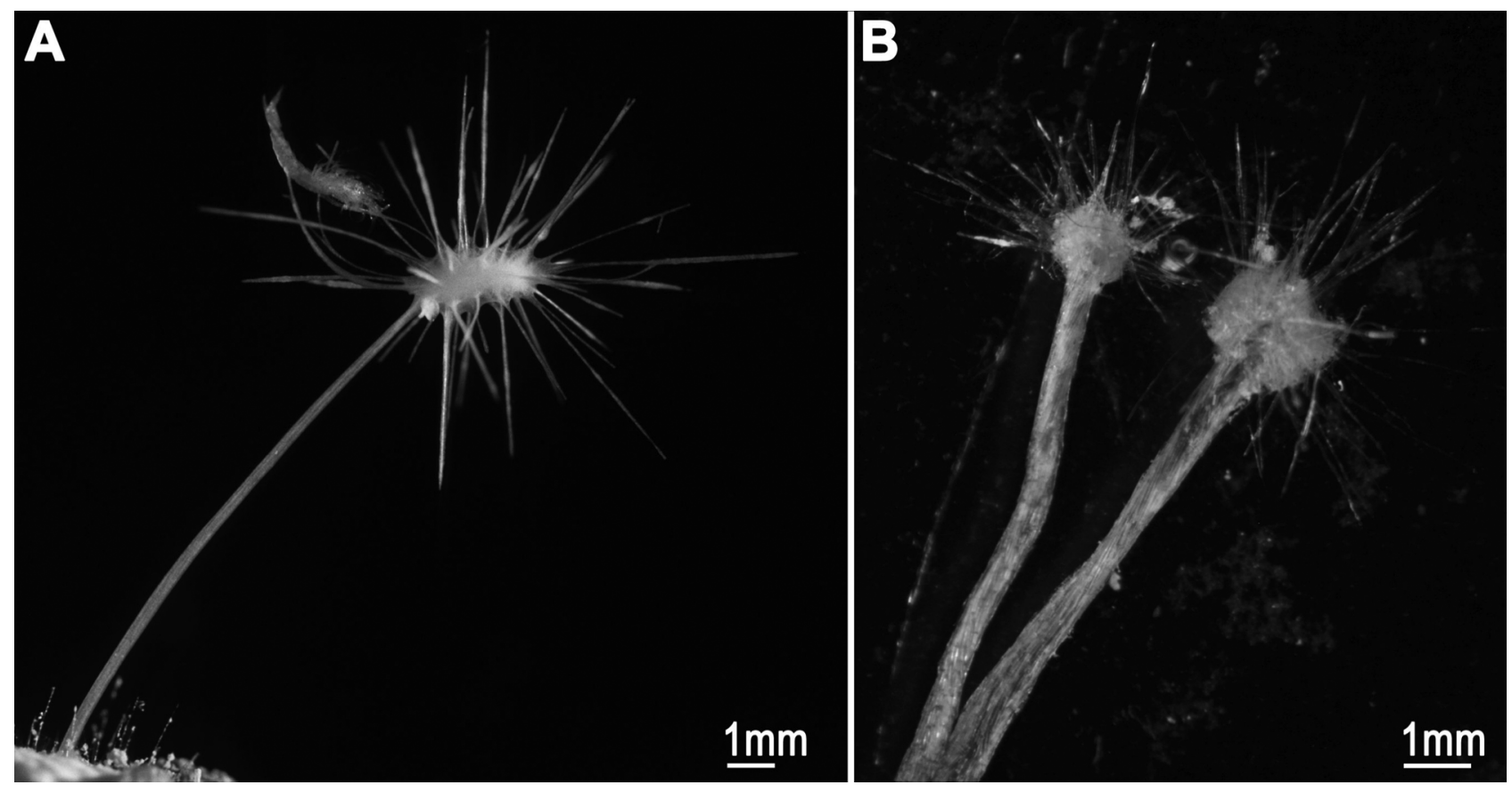

FIGURE 6. (A) View of the carnivorous sponge Asbestopluma hypogea soon after trapping a small copepod. The sponge is displaying the spiny-headed morphology, which is typical after a period of starvation in order to maximize the chances of new prey capture (Vacelet \& Duport 2004). (B) View of the capitate region of the holotype and the paratype of Spiculosiphon oceana sp. nov. for a comparison with the body shape of the carnivorous sponge. 
A further similarity with the feeding strategy of carnivorous sponges is that both in the case of the unicellular foraminifer and the multicellular sponges, macroprey are digested in the absence of any digestive tube or digestive cavity, relying only on an intracellular digestion process. The astonishing convergence between Spiculosiphon spp. and carnivorous sponges may have been favored by both organisms being partially subject to similar selective pressures: they are relatively small, sessile predators that need to find preys in relatively deep, oligotrophic environments. This idea is further supported by the finding that an undetermined Spiculosiphon species occurs in the same sublittoral, oligotrophic Mediterranean cave (3PP cave) where carnivorous sponges were first discovered to science (Vacelet \& Boury-Esnault 1995; Vacelet et al. 1994). Nevertheless, although the convergence between Spiculosiphon spp. and carnivorous sponges in body shape and prey capturing strategy is enormous, the fine mechanism developed to trap contacted prey is clearly different in both organisms. Carnivorous sponges rely on a hook-like microsclere lining (anisochelae, isochelae, sigmancistras, etc) that makes the surface of the radiating appendages to work as a "Velcro"-like, trapping system. In Spiculosiphon spp., the trapping of contacted prey would rather rely on the sticky nature of its cell membrane and glycocalyx, being the role of the spicules only limited to provide external skeletal support for enhancing pseudopodia extension.

In summary, Spiculosiphon spp. are suggested to use sponge spicules to recreate both the body shape and the prey capturing strategy developed by some carnivorous sponges. Indeed, the material herein studied of Spiculosiphon oceana sp. nov. was initially collected and sent to us under the assumption that it could be a nondescribed carnivorous sponge.

\section{Acknowledgements}

The authors thank María J. Carbonell (CEAB-CSIC) for her help with SEM and EDS analyses, Fundación Biodiversidad and Foundation for the Third Millenium for their generous funding support to the field expedition, and Oceana Ranger crewmembers for their efficient work during the cruise. The authors also thank Dr. Onno Gross for his tentative classification of the 3PP specimens some 18 years ago and two anonymous reviewers for their constructive comments on the original manuscript. This research has benefited from funds of the Spanish Ministry of Economy and Competitiveness grant (CTM2012-37787) to MM.

\section{References}

Allen, K., Stephen, R. \& Murray, J.W. (2000) Analysis of organic components in the test wall of agglutinated foraminifera by Fourier Transform Infrared and Pyrolysis Gas Chromatography/ Mass Spectrometry. In: Hart, M.B., Kaminski, M.A. \& Smart, C.W. (Eds.) Proceedings of the Fifth International Workshop on Agglutinated Foraminifera. Grzybowski Foundation Special Publication, pp. 1-13.

Ba, L.A., Döring, M., Jamier, V. \& Jacob, C. (2010) Tellurium: an element with great biological potency and potential. Organic \& Biomolecular Chemistry, 8, 4203-4216. http://dx.doi.org/10.1039/c0Ob00086h

Bender, H. (1995) Test structure and classification in agglutinated foraminifera. In: Kaminski, M.A., Geroch, S. \& Gasinski, M.A. (Eds.) Proceedings of the Fourth International Workshop on Agglutinated Foraminifera. Grzybowski Foundation Special Publication pp. 27-70.

Bowser, S.S., Gooday, A.J., Alexander, S.P. \& Bernhard, J.M. (1995) Larger agglutinated foraminifera of McMurdo Sound, Antarctica: Are Astrammina rara and Notodendrodes antarctikos allogromiids incognito? Marine Micropaleontology, 26, $75-88$. http://dx.doi.org/10.1016/0377-8398(95)00024-0

Cattaneo-Vietti, R., Bavestrello, G., Cerrano, C., Sara, M., Benatti, U., Giovine, M. \& Gaino, E. (1996) Optical fibres in an Antarctic sponge. Nature, 383, 397-398. http://dx.doi.org/10.1038/383397b0

Christiansen, B.O. (1964) Spiculosiphon radiata, a new Foraminifera from northern Norway. Astarte, 25, 1-8. DeMaster, D.J. (1981) The supply and accumulation of silica in the marine environment. Geochimica et Cosmochimica Acta, 45, $1715-1732$. http://dx.doi.org/10.1016/0016-7037(81)90006-5

Gaucher, C. \& Sprechmann, P. (1999) Upper Vendian skeletal fauna of the Arroyo de Soldado Group, Uruguay. Beringeria, 23, 55-91.

Groussin, M., Pawlowski, J. \& Yang, Z. (2011) Bayesian relaxed clock estimation of divergence times in foraminifera. Molecular Phylogenetics and Evolution, 61, 157-166. http://dx.doi.org/10.1016/j.ympev.2011.06.008 
Habura, A., Goldstein, S.T., Broderick, S. \& Bowser, S.S. (2008) A bush, not a tree: the extraordinary diversity of cold-water basal foraminifera extends to warm-water environments. Limnology and Oceanography, 53, 1339-1351.

http://dx.doi.org/10.4319/lo.2008.53.4.1339

Harwood, D.M. \& Gersonde, R. (1990) Lower Cretaceous diatoms from ODP leg 113 Site 693 (Weddell Sea). Part 2: Resting spores, Chrysophyceans cysts, and endoskeletal dinoflagellate, and notes on the origing of diatoms. In: Barker, P.F. \& Kennett, J.P. (Eds.) Proceedings of the Ocean Drilling Program. Scientific Results pp. 365-402. http://dx.doi.org/10.2973/odp.proc.sr.113.127.1990

Hedley, R.H. \& Wakefield, J.S.J. (1967) A collagen-like sheath in the arenaceous foraminifer Haliphysema (Protozoa). Journal of the Royal Microscopical Society, 87, 475-481. http://dx.doi.org/10.1111/j.1365-2818.1967.tb04525.x

Hohenegger, J. (2009) Functional shell geometry of symbiont-bearing benthic Foraminifera. Galaxea, Journal of Coral Reef Studies, 11, 81-89. http://dx.doi.org/10.3755/galaxea.11.81

Kamatani, A. (1971) Physical and chemical characteristics of biogenous silica. Marine Biology, 8, 89-95. http://dx.doi.org/10.1007/BF00350922

Kaminski, M.A. (2004) The year 2000 classification of the agglutinated foraminifera. In: Bubík, M. \& Kaminski, M.A. (Eds.) Proceedings of the Sixth International Workshop on Agglutinated Foraminifera. Grzybowski Foundation Prague, pp. 237255.

Lecroq, B., Lejzerowicz, F., Bachar, D., Christen, R., Esling, P., Baerlocher, L., Østerås, M., Farinelli, L. \& Pawlowski, J. (2011) Ultra-deep sequencing of foraminiferal microbarcodes unveils hidden richness of early monothalamous lineages in deep-sea sediments. Proceedings of the National Academy of Sciences, 108, 13177-12182. http://dx.doi.org/10.1073/pnas.1018426108

Lee, J.L. (2006) Algal symbiosis in larger foraminifera. Symbiosis, 42, 63-75.

Lipps, J.H. (1979) Test structure in Foraminifera. Annual Review of Microbiology, 27, 471-486. http://dx.doi.org/10.1146/annurev.mi.27.100173.002351

Loeblich, A.R. \& Tappan, H.N. (1988) Foraminiferal genera and their classification. Van Nostrand Reinhold Co., New York, $970 \mathrm{pp}$.

Maldonado, M., Carmona, M.C., Velásquez, Z., Puig, A., Cruzado, A., López, A. \& Young, C.M. (2005) Siliceous sponges as a silicon sink: An overlooked aspect of the benthopelagic coupling in the marine silicon cycle. Limnology and Oceanography, 50, 799-809. http://dx.doi.org/10.4319/lo.2005.50.3.0799

Maldonado, M., Ribes, M. \& Van Duyl, F.C. (2012) Nutrient fluxes through sponges: biology, budgets, an ecological implications. Advances in Marine Biology, 62, 114-182. http://dx.doi.org/10.1016/B978-0-12-394283-8.00003-5

Marszalek, D.S., Wright, R.C. \& Hay, W.W. (1969) Function of the test in Foraminifera. Gulf Coast Association of Geological Societies Transactions, 19, 341-352.

Pawlowski, J., Holzmann, M., Berney, C., Fahrni, J., Gooday, A.J., Cedhagen, T., Habura, A. \& Bowser, S.S. (2003) Early evolution of Foraminifera. Proceedings of the National Academy of Sciences, 100, 11494-11498. http://dx.doi.org/10.1073/pnas.2035132100

Rützler, K. \& Richardson, S. (1996) The Caribbean spicule tree: a sponge-imitating foraminifer (Astrorhizidae). Bulletin de l'Institut Royal des Sciences Naturelles de Belgique, 66 suppl., 143-151.

Sen Gupta, B.K. (2002) Systematics of modern Foraminifera. In: Sen Gupta, B.K. (Ed.) Modern Foraminifera. Kluwer Academic Publishers, Dordrecht and Boston, pp. 7-36.

Sperling, E.A., Robinson, J.M., Pisani, D. \& Peterson, K.J. (2010) Where's the glass? Biomarkers, molecular clocks, and microRNAs suggest a 200-Myr missing Precambrian fossil record of siliceous sponge spicules. Geobiology, 8, 24-36. http://dx.doi.org/10.1111/j.1472-4669.2009.00225.x

Tsuchiya, M., Gooday, A.J., Nomaki, H., Oguri, K. \& Kitazato, H. (2013) Genetic diversity and environmental preferences of monothalamous foraminifers revealed through clone analysis of environmental small $\mathrm{K}$ subunit ribosomal DNA sequences. Journal of Foraminiferal Research, 43, 3-13. http://dx.doi.org/10.2113/gsjfr.43.1.3

Vacelet, J. \& Boury-Esnault, N. (1995) Carnivorous sponges. Nature, 373, 333-335. http://dx.doi.org/10.1038/373333a0

Vacelet, J., Boury-Esnault, N. \& Harmelin, J.G. (1994) Hexactinellid Cave, a unique deep-sea habitat in the scuba zone. DeepSea Research I, 41, 965-973. http://dx.doi.org/10.1016/0967-0637(94)90013-2

Vacelet, J. \& Duport, É. (2004) Prey capture and digestion in the carnivorous sponge Asbestopluma hypogea (Porifera: Demospongiae). Zoomorphology, 123, 179-190. http://dx.doi.org/10.1007/s00435-004-0100-0

Yin, L., Xiao, S. \& Yuan, X. (2001) New observations on spiculelike structures from Doushantuo phosphorites at Weng'an, Guizhou Province. Chinese Science Bulletin, 46, 1828-1832. http://dx.doi.org/10.1007/bf02900561 